Filo. y Lingüí. 10(2): 89-95, 1984.

\title{
EL SENTIDO PROFUNDO DE LA POESIA EN UN TEXTO DE VICENTE ALEIXANDRE
}

Jorge Andrés Camacho Ramírez.

El conocido trabajo de Roman Jakobson "La lingüística y la poética" se ha convertido en punto de referencia importante en los estudios literarios. No sólo por la indicación metodológica que de él se desprende directamente sino, también, porque es fuente de enriquecedoras posibilidades, según creativas interpretaciones. De ahí que en torno a él hayan germinado valiosos estudios.

En el trabajo de Jakobson, el axioma fundamental -la función poética proyecta el principio de equivalencia del eje de la selección sobre el de la combinación - se aplica, como en él se declara, al poema que tiene una "matriz convencional", o sea, a un tipo de texto cuya versificación responde a un código definido: se excluye, en consecuencia, el verso libre. No obstante, la posibilidad de adaptarlo provechosamente a un texto en verso libre, como el poema que aquí tratamos, rinde frutos satisfactorios.

Por su parte, la equivalencia - quien dice equivalencias asume tanto semejanzas como oposiciones-que es el principio constructor del lenguaje poético y que remite, en última instancia, a un fecundo binarismo, no es solo ello, sino que, a la vez, se convierte en factor de significación profunda. El poema, que es "palabra en el tiempo", consigue con esta organización de oposiciones y similitudes, un juego dialéctico del que brota el significado. Muchas veces de la ruptura de un sistema que parece permanente (estático) surge lo que se ha llamado el sentido (1). Así, un sistema de oposiciones, planteado por el mismo texto, que sorpresivamente se resuelve en la conjunción (síntesis y similitud a la vez) o lo contrario, una similitud propuesta, que se desgarra en oposiciones, son esquemas frecuentes de la constitución significativa de un texto poético.

En los poemas "versolibristas", la ausencia de equivalencia de una "matriz convencional", es sustituida por llamativas e equivalencias sintácticas y léxicas, que orientan hacia su valor connotativo. E inclusive, aún en estos textos el discurso tiende, a veces, como si buscara instintivamente una matriz, a moldearse en surcos tradicionales (ritmos, medidas y otros efectos fónicos parecen imponerse como una necesidad poemática).

La poesía, hemos dicho, no hace equivalencias solo por exigencias tácticas de indole constructiva o meramente formal y eufónica. Estas, que son las más notorias, van más allá: suelen motivarse, es decir, unir los elementos de la expresión al contenido expresado, en feliz conjunción, que la lengua utilitaria ha perdido (2). En última instancia, una fuente fundamental, profunda, de la poesía, está en la necesidad de unir lo disjunto, causa de conflicto esencial en el ser humano, y también del ansia del exiliado por reintegrarse a las fuentes originales (3), de hacer en la creación un poco, como querían los surrealistas, la experiencia divina de conciliar los contrarios. La metáfora es el más intenso acto de lengua para conseguirlo. $Y$ aún cuando el poeta cante el desgarramiento (lo disfórico), el esfuerzo del lenguaje que lo alcanza, resulta eufórico (4) y bello en virtud de aquella feliz conjunción que hace que el poema haga ("poein") lo que dice.

Mas, no hay que hacerse ilusiones, el milagro se opera solo en el delicado recinto del poema; la dimensión redentora, eufórica, no llega a trascender más allá del acto de lengua, y ni la conciliación de contrarios, ni un auténtico "viaje a la semilla", ni la anulación del tiempo se hacen efectivos. La poesía ofrece así una tercera dimensión: no es el paraíso ya irrecuperable, ni tampoco el mundo ineluctablemente disjunto de su realidad presente; en ella, pero solo en ella, consigue el hombre efectuar la utópica conjunción. Por esto, todo poema, aún sin proponérselo, hace un poco arte poética, así como el niño o el fruto confirman la teoría de la herencia o de la generación. Sin embargo hay textos que poematizan esta vertebración teórica de la poesía, que, por otro lado, aseguradamente no agota todas sus posibilidades de significación profunda. Es el caso del poema "Madre, madre" de Vicente Aleixandre, perteneciente a Espadas como labios, que no solo propone, como apunta la filosofía del poeta en lo que se ha Ilamado su "Primera serie", una vuelta hacia un origen indiscriminado $y$ feliz simbolizado en lo marino, sino que, a la vez, ofrece una solución a 
esta tensión utópica: el poema mismo. En su aparente irracionalidad, característica de Espadas como labios el texto hace coherente, es decir, racional a nivel profundo, dicha significación (5).

\section{"MADRE, MADRE"}

La tristeza u hoyo en la tierra, dulcemente cavado a fuerza de palabra, a fuerza de pensar en el mar, donde a merced de las ondas bogan lanchas ligeras.

Ligeras como pájaros núbiles, amorosas como guarismos, como ese afán postrero de besar a la orilla, o estampa dolorida de uno solo, o pie errado.

La tristeza como un pozo en el agua, pozo seco que ahonda el respiro de arena, pozo. - Madre, ime escu chas? : eres un dulce espejo donde una gaviota siente calor o pluma.

Madre, madre, te llamo; espejo mío silente, dulce sonrisa abierta como un vidrio cortado. Madre, madre, esta herida, esta mano tocada, madre, en un pozo abierto en el pecho o extravfo.

La tristeza no siempre acaba en una flor, ni esta puede crecer hasta alcanzar el aire, surtir. - Madre, ime escuchas? Soy yo que como alambre tengo mi corazón amoroso aquí fuera.

Espadas como labios (6).

Observaciones iniciales: el poema consta de cinco estrofas (de cuatro versos cada una, excepto la número 4), de las cuales la inicial, la intermedia (número 3), y la final, presentan un recurso anafórico ("La tristeza..."). Este elemento, que propone en cada caso un complejo oracional cuyo sujeto es él mismo, permite una división del poema en tres partes (primera y segunda estrofas: primera parte; tercera y cuarta estrofas: segunda parte y quinta estrofa: tercera parte).

Si bien, como veremos, las posibilidades de acercamiento por similitud son significativamente notables en las tres partes, en las dos primeras son mucho más evidentes. Por ejemplo, el carácter sustancial y formal de nuevas equivalencias que inician estas dos partes:

La tristeza $=$ hoyo

La tristeza $=$ pozo

Estas dos primeras partes, igualmente, constituyen oraciones nominales. También, ambas cierran con elementos semánticamente equivalentes:

\section{"pie errado"}

"extravío"

Cada una de ellas tiene en el cuarto verso de su primera estrofa otro, casi imperceptible, elemento anafórico: el adverbio "donde", que en ambos casos introduce una subordinada que remite a la interioridad del espacio marino:

"donde a merced de las ondas bogan lanchas ligeras"

"donde una gaviota siente calor o pluma"

Entre la segunda y la tercera parte hay nuevas similitudes: la pregunta sin respuesta ("Madre, ¿me escuchas?"). Y la subsiguiente definición de cada uno de los protagonistas del poema:

"Eres un dulce espejo..."

"Soy yo..."

Sin embargo, la tercera parte, que analizaremos más adelante, aparentemente al menos, rompe el esquema propuesto por los dos anteriores. La última parte del texto ha de culminar, según la esencial temporalidad del poema, su sentido.

EI análisis semántico revela la constitución binaria del poema, que se sustenta en el correlato de los personajes del texto, madre e hijo, confirmados gramaticalmente en el yo y en el tú de las oraciones correlativas "Soy yo...", "Eres...".

Este esquema binario propone un campo de oposiciones semánticas: así, "madre", por relación metafórica es equivalente a "dulce espejo", y este a su vez, a "mar"; de lo cual se infiere la relación madre $=$ mar. El mar, en lo que se ha llamado la primera serie de la poesía de Aleixandre, se constituye en el símbolo del anhelado paraíso perdido, en edípica utopía, en el origen de la elementalidad feliz.

La madre-mar, por consecuentes razones es también amor, como lo expresa este fragmento de "Hija de la mar" de La destrucción o el amor:

\footnotetext{
"Vive, vive como el mismo rumor de que has nacido; escucha el son de tu madre imperiosa:

Sé tú espuma que queda después de aquel amor, después de que, agua o madre, la orilla se retira", (7).
}

El trinomio madre-mar-amor despliega toda una red de relaciones ya metafóricas o por sinécdoque o metonimia, que acentúan la oposición descrita entre los "protagonistas". Las expresiones "lanchas ligeras", "pájaros núbiles", "amorosas", "besar" (la ola = "afán postrero de besar la 
orilla"), "dulce espejo", "calor", "dulce sonrisa", aparecen asociadas, por cualesquiera de los recursos expuestos, al ámbito marino, cuyo matiz semántico es el eufórico del amor. $Y$ es ahí donde se encuentran significativamente la animalidad ("pájaros núbiles", "gaviota"), la pluralidad ("Ianchas ligeras", "pájaros núbiles") y la conjunción, de por sí, eufórica. Esta no solo está en "pájaros núbiles" y en el "afán de besar", etc., sino inclusive en ese sorprendente "amorosas como guarismos", que aprovecha el sema "conjuntividad" para establecer la ecuación.

El yo, por el contrario, está metonímicamente asociado a la tristeza y ésta, a la vez, metafóricamente, a "hoyo en la tierra", a "pozo seco", de lo cual se desprende otra importante relación metonímica:

$$
\text { yo-tierra, }
$$

cuyo esquema refuerza "orilla" (="estampa dolorida de uno solo"): "orilla" está, a la vez asociado a "arena", a "tierra", a lo seco ("pozo seco") y, en una palabra, a lo disfórico. De lo cual se deduce un nuevo trinomio semántico:

$$
\text { yo-tierra-tristeza }
$$

El yo, además, ostenta atributos esenciales de lo humano: la palabra ("la tristeza u hoyo... dulcemente cavado a fuerza de palabra") y el pensamiento ("a fuerza de pensar en el mar"). Comporta también el ámbito del yo, la singuralidad gramatical y semántica ("estampa dolorida de uno solo") y la disjunción: el yo se muestra segregado ("solo", "pie errado", "extravío", "orilla"), del espacio eufórico de la madre-mar. El hacer con la palabra ("cavado a fuerza de palabra") identifica al yo con el poeta, sentido que resulta piedra angular en la interpretación del texto.

Queda por considerar finalmente, una palabra clave en el poema, la que lo clausura: "fuera". El lexema, que hace paradigma con "orilla", "tierra" y "arena", por el mismo motivo, lo establece también con "extravío" y "pie errado", con lo cual se agrega un nuevo factor de equivalencia, justamente al final de cada una de las tres partes (véase el cuadro número 3 ).

El esquema fundamental de la oposición binaria puede hacerse de la siguiente forma:

\section{CUADRO No. 1}

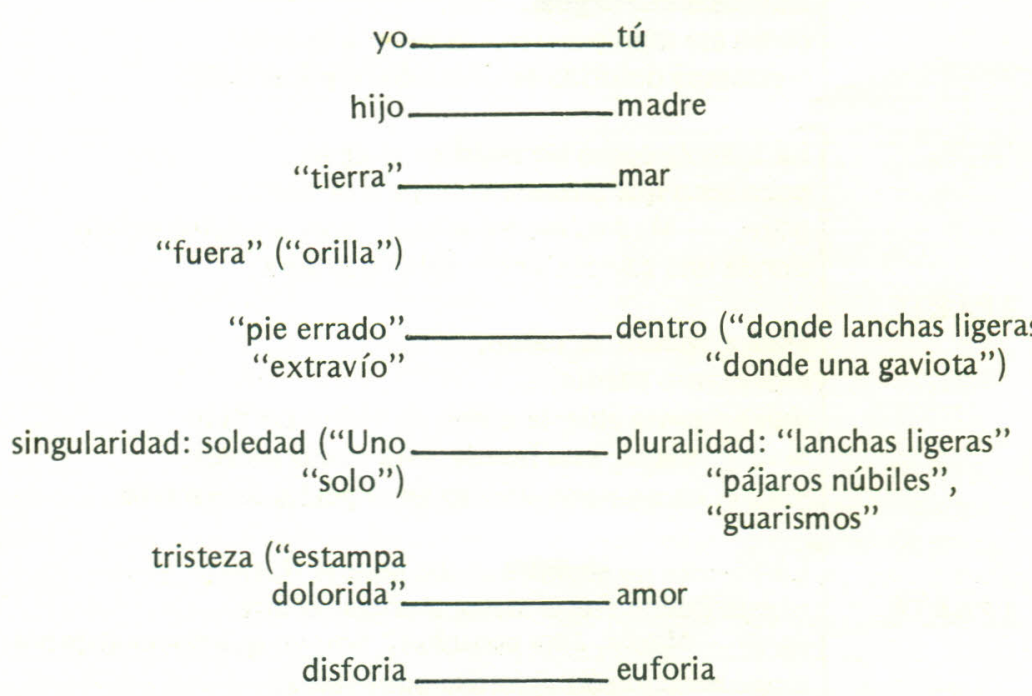

Inclusive en vista de los vínculos semánticos que se dan entre los signos "madre" e "hijo", es razonable encontrar elementos semejantes, aunque según el campo, aparezcan como disfóricos o como eufóricos. Así, la "madre", "dulce espejo", por relación metafórica con "mar", es espejo también del hijo: "espejo mío silente". En el cuadro las imágenes confrontadas permiten también entrever una relación de causa a efecto: 
CUADRO No. 2

\author{
madre _ yo \\ (dulce) espejo_ espejo mío \\ "como un vidrio cortado"_ "esta herida" esta mano tocada" \\ (dulce) sonrisa abierta “_pozo abierto"
}

El ansia amorosa del hijo hacia la madre justifica, de acuerdo con una tradicional imagen, "esta herida... [en un pozo abierto] en el pecho".

Considerando la abstracción euforia con el signo (+) y la disforia con el signo ( -$)$, factores estos a los que en última instancia puede reducirse el esquema binario madre-hijo, se podría establecer el siguiente cuadro, según se distribuyan estos signos en las estrofas y las partes que constituyen:

\title{
CUADRO No.3
}

$\left.\begin{array}{l}1 \text { PARTE }\left[\begin{array}{l}\text { La tristeza u hoyo en la tierra, } \\ \text { dulcemente cavado a fuerza de palabra, } \\ \text { a fuerza de pensar en el mar, } \\ \text { donde a merced de las ondas bogan lanchas ligeras. } \\ \text { Ligeras como pájaros núbiles, } \\ \text { amorosas como guarismos, } \\ \text { como ese afán postrero de besar a la orilla, } \\ \text { o estampa dolorida de uno solo, o pie errado. }\end{array}\right. \\ 2 \text { PARTE }\left[\begin{array}{l}\text { La tristeza como un pozo en el agua, } \\ \text { pozo seco que ahonda el respiro de arena, } \\ \text { pozo. --Madre,ime escuchas? : eres un dulce espejo } \\ \text { donde una gaviota siente calor o pluma. } \\ \text { Madre, madre, te llamo; } \\ \text { espejo mío silente, } \\ \text { dulce sonrisa abierta como un vidrio cortado. } \\ \text { Madre, madre, esta herida, esta mano tocada, } \\ \text { madre, en un pozo abierto en et pecho o extravío. }\end{array}\right] \\ 3 \text { PARTE }\left[\begin{array}{l}\text { La tristeza no siempre acaba en una flor, } \\ \text { ni esta puede crecer hasta alcanzar el aire, } \\ \text { surtir. -Madre, ime escuchas? Soy yo que como alambre } \\ \text { tengo mi corazón amoroso aquí fuera. }\end{array}\right]\end{array}\right]$

Como se ve, la simetría de las dos primeras partes resulta léxica y gramaticalmente extraordinaria, de manera que se da una alternancia cíclica que profundiza su semejanza. $Y$ como es de esperar, estas simetrías léxicas y gramaticales apuntan a simetrías semánticas. La última parte, por el contrario, rompe el formato, en vista de que toda ella pertenece al ámbito del yo. Lo que se 
desprende del cuadro anterior es que el sentido del texto parece arribar a un valor totalmente disfórico. La madre, espejo "silente", a la que se le apela en insistentes preguntas sin respuesta ("Madre, ¿me escuchas? "), es espacio inalcanzable para el hijo que ha "errado" ("extravío") sus pasos, según el sentimiento que anima buena parte de la visión del hombre, en la serie aleixandrina a la que pertenece el texto.

Sin embargo, el locativo "fuera" del final ofrece una importante ambigüedad (la ambigüedad es lícita y necesaria en la poesía). "Fuera" que entra en paradigma contextual con "extravío", "orilla", "tierra", "pie errado", en contraposición al dentro ("donde a merced de las ondas..." "donde una gaviota") de la esfera marina, hace también paradigma contextual en su estrofa, por el sema común "superatividad", con los lexemas "flor", "crecer", "aire", "surtir", "alcanzar", contrapuesto al paradigma que sustentaría el sema "inferatividad": "hoyo", "pozo", "ahonda", "cavado".

De manera que la tristeza ("pozo cavado a fuerza de palabra" = inferatividad) algunas veces ("no siempre") acaba en flor (superatividad), que de acuerdo con nuestra interpretación constituye un símbolo de la poesía, específicamente del poema. EI lexema "fuera" enriquece entonces su sentido con valor eufórico ("fuera" \pm ). La tristeza, por una profunda significación del texto es equivalente a flor. En el cuadro, se muestra el itinerario de estas transformaciones. Las líneas verticales indican la dirección metafórica y las horizontales, la metonímica.

\section{CUADRO No. 4}

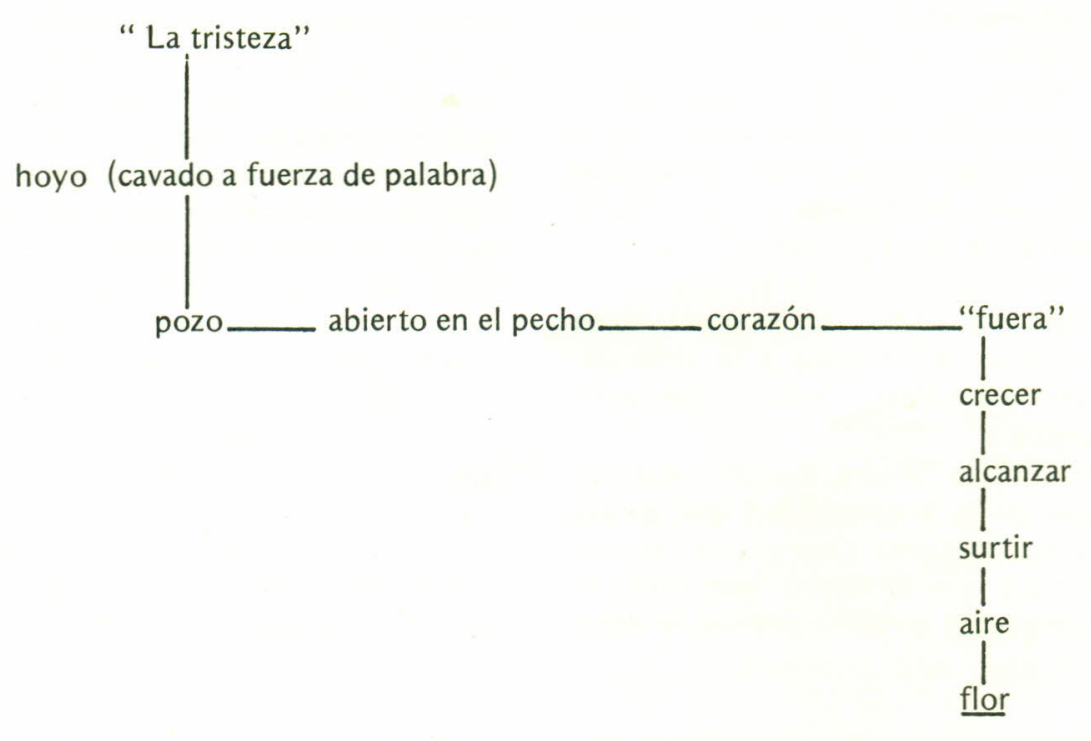

En su primera proyección significativa (la disfórica), "fuera" conforma una oposición de horizontalidad (primera dimensión: dentro: euforia; segunda dimensión: fuera: disforia) que principalmente, remite, desde luego, a lo espacial, pero podría portar posibilidades de significación temporal, dado el carácter incoativo o ingresivo de "extravío" o "pie errado", que según señalamos constituyen paradigma con "fuera". Aquí, el valor disfórico que "fuera" impone, alude a un irreconciliable distanciamiento en el espacio y en el tiempo.
La otra orientación paradigmática de "fuera", la eufórica ("alcanzar", "surtir", "aire", "flor"...) es, digamos así, la verticalidad, donde se da la tercera dimensión de la que hablamos al inicio de este trabajo (Ilámase sublimación, capacidad creadora del hombre en el arte, del poeta que transmuta las amarguras viejas "en blanca cera y dulce miel" como decía Machado). Entonces el exiliado puede hacer, paradójicamente suyos los atributos eufóricos ("mi corazón amoroso") de la madre-mar, en significativa síntesis que concilia la oposición antitética mencionada en el páırafo anterior. 
CUADRO No. 5

\section{3a. dimensión}

Ia dimensión

Para concluir, solo resta mostrar cómo en este poema "versolibrista", los paradigmas semánticos que contribuyan a esclarecer su sentido, también, en sorprendente conjunción, hacen paradigmas fónicos, los cuales, independientemente de que el poeta se lo propusiera o no, constituyen la realidad, ya ineludible, del texto. Sin entrar a considerar efectos paranomásicos del corte de "ligeras como pájaros núbiles" o "amorosas como guarismos", o rimas internas ("pensar... en el mar", "orilla dolorida"), hay en los paradigmas textuales que conducen la mayor carga significativa del poema, una interesante vinculación fónica. Así, señalando la vertiente disfórica hacen paradigma fónico "tristeza", "tierra", "arena", "fuera".

Otro paradigma fónico muestra el itinerario de la transmutación de lo disfórico a lo eufórico: "hoyo", "pozo" (4 veces), "solo", "soy yo", "corazón", "amoroso", "flor".

En resumen, el texto "Madre, madre", de difícil lectura, a causa de la irracionalidad que parece infundirlo, resulta altamente coherente y racionalizable. Tal vez sea que el interés que cobra lo irracional (lo elemental) en nuestra época, se deba, en parte, al alto grado de conocimiento y racionalización que se ha dado al respecto.

Dicha coherencia, que inclusive puede expresarse con la imagen de la incoherencia, es necesaria para que cualquier texto cumpla el cometido de significar, y más aún cuando se trata de un poema, en el que el significado parte desde cualquier indicación formal. Entonces, a pesar de la ruptura de formas tradicionales de versificación, en las cuales un despliegue de equivalencias de diversa índole buscan "iconizar" su sentido, el poema en verso libre tiende a cristalizar nuevas equivalencias formales, aunque sin prescindir enteramente de las que generaban aquellas formas. Parece una necesidad en la conformación del sentido poético.

En esta proyección de equivalencias el poema valoriza (semantiza) la redundancia natural de la lengua.

Por otro lado, la poesía es también redundante en las matrices profundas de significación que la nutren, generadoras de indefinidas series de textos, si bien algunos investidos con la expresión del irracionalismo, y otros con las más lúcidas y acabadas imágenes. Así, "Madre, madre", retoma dos importantes fuentes de poetización: en primer lugar, la que metaforiza el propio poema en flor: "es una flor que quiere/echar su aroma al viento", dice A. Machado en "Introducción" de "Galerías"; también Juan Ramón: "El poema": "No lo toques ya más, que así es la rosa". En segundo lugar, e inseparable de lo anterior, la capacidad creadora del poeta que transmuta el dolor humano, embelleciéndolo, en arte: en el mismo poema Machado dice: "la nueva miel labramos con los dolores viejos". Así, en el texto de Aleixandre, la tristeza, dulcemente cavada a fuerza de palabra, algunas veces surte, se manifiesta en flor, en poema (8).

\section{CITAS BIBLIOGRAFICAS}

(1) 'El 'sentido' es... el objeto específico de la investigación, en cuanto que sobre él se eleva todo el edificio formal del texto artístico", afirma J. Talens, siguiendo a Emilio Garroni en "Introduzione cuasi teorica" a Pinocchio uno e bino. Talens, J. Elementos para una semiótica del texto artístico, Ediciones Cátedra S.A., Madrid, 1978, págs. 28 y siguientes.

(2) El concepto de motivación, que tan lúcidamente había propuesto Dámaso Alonso, y sus posibilidades metodológicas ha sido ampliamente considerado por la nueva crítica. Así, por ejemplo, Gérard Genette dice: "... la función poética reside precisamente en ese esfuerzo por "remunerar", aunque fuera ilusoriamente, la arbitrariedad del signo, es decir, por motivar el lenguaje". "Lenguaje poético, poética del lenguaje" en Barthes, Roland y otros. Estructuralismo y Literatura, Ediciones Nueva Visión, Buenos Aires, 1972, págs. 73 y siguientes.

(3) "La emoción del hombre primitivo que recreaba un objeto al denominarlo, con lo cual se lo apropiaba, aún está implícita en la poesía. Muchas son las palabras de un poema que parecen surgir directamente de la "fuente"; dan la impresión de que se las pronuncia por primera vez, en ese contexto particu- 
lar y con esa particular significación. La palabra de un poema es joven, limpia, intacta, como si una oculta realidad acabara de cristalizar en ella", dice Ernst Fischer en Lenguaje y arte, Rodolfo Alonso Editor, Buenos Aires, 1972, pág.34.

(4) "Si la comunicación poética, indudablemente, es en su conjunto creadora de euforia, es incontestable que la sustancia fonética y semántica, objeto de esta comunicación, se halla connotada al nivel de todas sus articulaciones, por la categoría propioceptiva manifestando ya su término eufórico, ya su término disfórico. La aparente contradicción podría disiparse si se admitiera, como lo hemos propuesto, la existencia de la significación de las formas poéticas, distinta de la significación de la substancia: mientras que la substancia está connotada por las variaciones isotópicas a la vez eufóricas y disfóricas, la forma poética, manifestada fundamentalmente por la redundancia y la adecuación de la expresión y del contenido, al provocar los "efectos de sentido" de permanencia y de verdad, sería pura euforia". Afirman A. Greimas en "Las relaciones entre la lingüística y la poética", André Georges Haudricourt y otros, Estructuralismo y lingüistica, Ediciones Nueva Visión, Buenos Aires, 1971, págs. 177.

(5) En esto coincidimos con el artículo de Alejandro Amusco "Lectura de un texto de Aleixandre", en Cuadernos Hispanoamericanos, No.313, julio de 1976 , pág.167.

(6) Vicente Aleixandre: Obras completas. Aguilar S. A. Madrid, 1968, pág.285.
(7) De "Hija de la mar" de La destrucción o el amor, Ibid, pág.419. De igual manera... la madre-amor se desborda besando en oleadas la arena, es decir, las playas, que resultan metonímica representación de lo humano ("Arena, arena tu clamor es mío/Por mi sombra no existes como seno"). "Siempre" Espadas como labios (pág.284). La imagen del beso (sinécdoque de amor) del mar "como un corazón desbordante", sobre las playas, o la sequedad humana, se repite con frecuencia a través de la serie:

"Un mar como dos labios por la arena", "Orillas del mar" La destrucción o el amor (pág.356).

"Esos siempre reales labios con que sueño..." "Cobra" de La destrucción o el amor (pág.407).

"Quién dijo acaso que la mar suspira,

labio de amor hacia las playas, triste?" "El mar" Sombra del Paraiso (pág.557).

(8) En lengua inglesa este texto de Williams retoma, de otra manera, el motivo:

\author{
"Poem" \\ The rose fades \\ and is renewed again \\ by its seed, naturally \\ but where \\ save in the poem \\ shall it go \\ to suffer no diminution \\ of its splendor
}

Citado por Charles O. Hartman en "New Literary History" 13 (2) 1982, pág.337. 
